\title{
Territorialidad y conflicto \\ en un contexto minero: el caso del municipio de Marmato, Caldas*
}

\author{
Territority and conflict in a minig context: in the context of \\ Marmato, Caldas
}

\section{Territorialidade e conflito num contexto mineiro: o caso do município de Marmato, Caldas}

\section{Mónica Ramírez Guerrero** • Colombia}

Recibido el 29 de febrero de 2012, aceptado el 14 de mayo de 2012

\section{Resumen}

Objetivo: analizar la relación entre las dinámicas de la minería local, el arraigo territorial y los conflictos generados por el plan de minería a gran escala en el municipio de Marmato (Caldas, Colombia). Metodología: estudio de carácter cualitativo que se sitúa primordialmente en el método etnográfico para analizar los antagonismos frente a la minería y el territorio y se apoya en revisión de fuentes secundarias e históricas. Resultados: se constató que la minería de gran escala está generando la conversión del territorio, social y culturalmente dotado de relaciones y significados, en tierra vacante, valorada según la racionalidad mineralógica y económica. El megaproyecto minero en el municipio, que implicaría el reasentamiento de la población, ha trastocado el ritmo de la vida local y ha producido movimientos de resistencia ante un reordenamiento del territorio orientado "desde arriba". Una concepción hegemónica del territorio como vector de competitividad, lo estima social y culturalmente "sacrificable". Para la población local es necesario defender su continuidad y su identidad arraigada en la minería. Conclusiones: mientras empresas y Estado promocionan la gran minería como camino certero para el desarrollo económico del país, en Marmato se avivan los conflictos de interés y los procesos de resistencia por las posibles transformaciones paisajísticas, ambientales, económicas, culturales y de la propia dinámica social, que ocasionaría un proyecto de tal magnitud.

Palabras claves: minería, territorio, conflicto minero, resistencia social

* Este artículo se deriva de la tesis de maestría en Desarrollo Regional y Planificación del Territorio de la Universidad Autónoma de Manizales, titulada “Territorio, minería y conflictos del desarrollo. Estudio de caso en el municipio de Marmato, Caldas". Una primera versión de este artículo fue publicada bajo el título: "Territorio, minería y conflictos del desarrollo. Análisis de caso del municipio de Marmato, Caldas”. En: RegionEs, Vol. 6 N 1, julio de 2011, pp. 151-182.

** Magíster en Desarrollo regional y planificación del territorio. Antropóloga. Investigadora del Centro de Estudios Regionales Cafeteros y Empresariales (Colombia).mramirez@crece.org.co 


\section{Abstract}

Objective: To analyze the relationship between the dynamics of local mining, the territorial roots and the conflicts generated by the plan of mining on a large scale in the town of Marmato (Caldas, Colombia). Methodology: The qualitative approach study mainly lies on the ethnographic method to analyze the antagonism against the mining and the territory and it is based on the revision of secondary and historical sources. Results: It was found that large scale mining is changing the territory, socially and culturally endowed of relations and meanings, on available land, valued according to mineralogical and economic rationality. The mega-mining project in the town, which would involve the resettlement of the population, has altered the pace of local life and has produced resistance movements to a reordering of the territory-oriented "from up". A hegemonic territory conception as a vector of competitiveness, considers it socially and culturally "sacrificeable". For the local population is necessary to defend its continuity and identity rooted in mining. Conclusions: While the companies and the State promoted the great mining as an accurate way for the economic development of the country, in Marmato, there will be conflicts of interest and resistance to the possible landscape, environmental, economic and cultural transformations and processes of the social dynamics due to huge project.

Key words: Minig, territory, mining conflict, social resistance.

\section{Resumo}

Objetivo: analisar a relação entre as dinâmicas da mineração local o arraigo territorial e os conflitos gerados pelo plano de mineração a grão escada no município de Marmato (Caldas Colombia). Metodologia: estudo de caráter qualitativo que situa se primordialmente no método etnográfico para analisar os antagonismos frente à mineração e o território e apoia se em revisão de fontes secundárias e históricas. Resultados: Constatou se que a mineração de grão escada está gerando a conversão do território, social e culturalmente dotado de relações e significados, em terra vacante, valorada segundo a racionalidade mineralógica e econômica. O megaprojeto mineiro no município que implicaria o reassentamento da povoação tem interrompido o ritmo da vida local e tem produzido movimentos de resistência ante um rearranjo do território orientado "desde arriba". Uma concepção hegemônica do território como vetor de competitividade, o estima social e culturalmente "sacrificável" Para a povoação local é necessário defender sua continuidade e sua identidade arraigada na mineração. Conclusões: enquanto empresas e Estado promovem a grão mineração caminho certeiro para o desenvolvimento econômico do país, em Marmato avivam se os conflitos de interes e processo de resistência pelas possíveis transformações paisagísticas, a ambientais, econômicas, culturais e de a própria dinâmica social, que ocasionaria um projeto de tal magnitude.

90 Palavras chaves: mineração, território, conflito mineiro, resistência social.

Para

citar este artículo:
Ramírez G., M. (julio - diciembre 2012). Territorialidad y conflicto en un contexto minero: el caso del municipio de Marmato, Caldas. Ánfora, 19 (33), 89 - 113. Universidad Autónoma de Manizales. ISSN 0121-6538. 


\section{Introducción}

La importancia que históricamente se ha concedido al oro es incuestionable. Distintas culturas han hecho usos muy diversos del oro: símbolo de riqueza, medio de intercambio y de acumulación, metal sagrado y materia prima privilegiada para la joyería. También es conocido su papel en el desarrollo tecnológico, a través de aplicaciones médicas, electrónicas y nanotecnologías. Durante el siglo XIX, el sistema monetario internacional estuvo fundamentado en el oro. Asimismo, la oferta monetaria nacional estuvo ligada a la convertibilidad de la moneda en oro y el déficit comercial era saldado por los países deudores mediante la exportación de oro. Aunque en la actualidad no es el soporte del sistema financiero mundial, el oro sigue teniendo un papel preponderante en dicho sistema ${ }^{1}$.

América Latina despierta hoy un gran interés para la minería transnacional del oro. El alza en el precio de este metal, la creciente demanda de minerales en países como China e India, el agotamiento de fuentes auríferas en otras regiones del planeta y el uso de marcos regulatorios amables para incentivar la inversión extranjera, han hecho de este continente un destino importante para las exploraciones de metales preciosos. A comienzos de los años noventa la región representaba alrededor del 12\% de los inversiones mundiales en el sector minero; actualmente esta proporción corresponde a un tercio (Mazure, 2010). En Colombia, el Plan Nacional de Desarrollo Minero 2019 (PNDM 2019) contempla que para el 2019, la industria minera en el país se ubicará entre las más importantes de Latinoamérica, cuadriplicando la producción actual de metales preciosos.

La extracción y manejo de recursos estratégicos, como el oro, alrededor del mundo, ha convertido las comunidades locales en escenarios conflictivos (Bebbington, Hinojosa, Humphreys, Burneo y Warnaas, 2008). El panorama se hace más complejo cuando confluyen o se superponen distintas modalidades extractivas (de pequeña y gran escala, artesanal y tecnificada, local y multinacional). Este artículo presenta los resultados de un estudio de carácter cualitativo sobre el conflicto minero en Marmato, municipio ubicado en la zona noroccidental del departamento de Caldas, generado por el proyecto de megaminería aurífera, de una empresa canadiense. Marmato es el centro aurífero más importante de Caldas, departamento que se ubicó en el tercer lugar, después de Antioquia y Bolívar, en producción de oro durante el periodo 2006-2010 (Centro de Iniciativas Mine-

1 De acuerdo con el Fondo Monetario Internacional: "El oro desempeñó un papel decisivo en el sistema monetario internacional hasta 1973, cuando se desintegró el mecanismo de tipos de cambio fijos creado en Bretton Woods. Desde entonces, su influencia ha menguado poco a poco. Sin embargo, continúa siendo un activo importante de las tenencias de reservas de varios países, y el FMI es uno de los mayores tenedores oficiales de oro del mundo". Para ampliar esta referencia puede visitarse el portal del FMI, http://www.imf.org/external/np/exr/facts/spa/golds.htm 
ras, 2010). Forma parte del distrito minero del mismo nombre ${ }^{1}$, que comprende además los municipios de Supía, Riosucio, La Merced y Filadelfia, los cuales poseen un menor aporte productivo. El distrito minero de Marmato es uno de los 43 distritos existentes en Colombia y aporta cerca del 7\% de la producción de metales preciosos, de la cual un $75 \%$ ha sido producido por una empresa (Mineros Nacionales, clasificada como mediana minería) y el 25\% restante proviene de los pequeños mineros (UPME, 2007).

La realización de dicho megaproyecto - que actualmente se encuentra en su fase exploratoria- implica el reasentamiento de la cabecera municipal, así como la desaparición de la minería de pequeña escala, práctica económica y social consuetudinaria. Frente al megaproyecto metalífero, se ha creado un movimiento de defensa del territorio municipal, por las previsibles transformaciones paisajísticas, ambientales, económicas, culturales y de la propia dinámica social que ocasionaría. Dicho movimiento trasciende las fronteras municipales y hace parte de una postura contestataria más amplia frente a la gran minería en distintas regiones del país y América Latina.

\section{Metodología}

Marmato se ubica en la región Alto Occidente del departamento de Caldas, sobre la vertiente oriental de la cordillera occidental y la vertiente occidental de la hoya del río Cauca; dista 142 kilómetros de Manizales, la capital del departamento. El trabajo de campo en el municipio fue realizado durante varios periodos de 2009 , haciendo uso de técnicas de observación, entrevistas abiertas y en profundidad y grupos de discusión. La población consultada es diversa: docentes, obreros y empresarios mineros, jóvenes estudiantes, comerciantes, amas de casa e integrantes del Comité Prodefensa de Marmato y de la Cooperativa de Mineros. Así mismo, se consultaron las posturas institucionales, a través de entrevistas con funcionarios de la Alcaldía Municipal, la Gobernación de Caldas y la Corporación Autónoma de Caldas. Un segundo componente de la recopilación de información implicó la revisión exhaustiva de documentación procedente de la prensa local y nacional, y de portales en Internet de algunas de las organizaciones ambientalistas más representativas y activas en su lucha en contra de la gran minería en

1 Los distritos mineros son una forma de denominación de territorios subregionales, áreas geológicas más o menos homogéneas con presencia de algún tipo de mineralizaciones susceptibles de explotación económica, en los cuales se concentra de manera significativa la actividad minera.

2 Caldas es uno de los tres departamentos que conforman, con Risaralda y Quindío, la región conocida como Eje Cafetero, en los Andes Centrales de Colombia.

3 El procedimiento para realizar las entrevistas consistió en establecer un primer contacto con algunas personas involucradas más directamente en el proceso de debate y resistencia al megaproyecto minero y al reasentamiento de la población; a través de ellas se realizaron nuevos contactos. Posteriormente, y de manera más aleatoria, fueron consultados otros pobladores. El criterio para su selección fue su disposición a abordar los temas propuestos. Por razones de confidencialidad, cuando se cita textualmente a los entrevistados, sólo se hace referencia al sexo y a la edad. 
América Latina (como No a la Mina y Observatorio de Conflictos Mineros). De igual manera, se revisaron informes técnicos del Ministerio de Minas y Energía, la Unidad de Planificación Minera y Energética, el Instituto Colombiano de Geología y Minería (Ingeominas), el Ministerio del Medio Ambiente, Vivienda y Desarrollo Territorial, el Esquema de Ordenamiento Territorial del municipio y el Plan de Desarrollo Municipal vigentes, entre los más importantes. Finalmente, se realizó una exploración de la legislación colombiana en materia de minería y ordenamiento del territorio.

\section{Resultados}

Para una mejor comprensión del caso de Marmato, es necesario ubicar el conjunto de circunstancias que ha desencadenado el conflicto minero en el marco de la expansión de la gran minería en Colombia y América Latina, y su articulación con la reivindicación del territorio y los derechos de propiedad consuetudinaria de las poblaciones locales; aspectos que se señalan enseguida.

Según el informe de destinación presupuestal para exploración metalífera en el mundo, realizada por Metals Economic Group, en 2009, Colombia se ubicó entre los países latinoamericanos en los que existe mayor interés de inversión, después de Perú, México, Chile, Brasil y Argentina. La minería del oro en el país ha tenido un renovado interés y es en la actualidad una de las principales apuestas económicas y políticas del gobierno. La transformación del país en "destino minero", pone el acento la participación de inversionistas privados, limitando el campo de la intervención estatal. La visión de "Colombia minera" plasmada en el PNDM 2019 muestra claramente esta tendencia: "El foco de la gestión estatal para el sector debe ser la generación de un ambiente de atención al cliente que avive su confianza en el país y motive mayores inversiones en la exploración y el desarrollo de proyectos mineros" (Unidad de Planeación Minero Energética, 2007, p. 9).

\section{Historia de un conflicto minero}

A mediados de la pasada década, surgió en la escena local una compañía canadiense, Colombian Goldfields; inició exploraciones para determinar el potencial aurífero en la zona, y posteriormente planteó su intención de llevar a cabo un gigantesco proyecto, “The Marmato Montain Development", en la zona del cerro. En este proyecto se removerían entre 30 y 60 mil toneladas diarias de mineral, roca y tierra, para obtener una producción anual de 250 mil onzas de oro ${ }^{1}$ (Grajales y Reyes, 2008). Un proyecto de tal magnitud implica la desaparición del pueblo y de la minería artesanal y de pequeña escala.

\footnotetext{
1 Onza troy es una medida utilizada para los metales preciosos y es equivalente a 31 gramos. La evolución del precio del oro, desde 1998 hasta hoy, puede consultarse en http://www.gold.org/ investment/statistics/prices/
} 
Posteriormente, esta compañía compró parte de las minas, aproximadamente 120, de un total de 252. Muchos cuestionaron las estrategias de la compañía para instarlos a la venta: "Los abogados de la empresa le decían a los mineros que aprovecharan para vender esas minas porque después no les iba a tocar un peso, y decían que ellos iban a pedir esas minas para ellos y que el gobierno se las iba a dar; entonces ellos vendieron porque es mejor recibir algo ahora que nada después, fue una jugada muy sucia para los mineros" (Hombre, 66 años). Posteriormente la propia compañía cerró las minas adquiridas y destruyó las plantas de beneficio del oro que también había obtenido, generando una crisis de desempleo y un ambiente hostil entre la población hacia la compañía por estos hechos, así como incertidumbre frente al futuro del pueblo. La compañía arguyó que esta decisión se debía a los problemas ambientales que estaba generando la minería de pequeña escala: "Los pequeños mineros vierten continuamente en el río local. Estos vertimientos están llenos de cianuro, mercurio, arsénico. Apenas controlamos una planta, la cerramos y poco a poco vamos a acabar con esto y limpiarlo", afirmó el presidente de la compañía ${ }^{1}$.

El cierre de las minas y la ausencia de frentes de trabajo provocó lo que en Marmato se denomina guacha: los mineros desempleados empezaron a extraer oro de forma ilegal, rudimentaria, sin control y sin medida de seguridad alguna. Esta práctica también atrajo a personas ajenas al pueblo, con experiencia en minería o sin ella, que vieron esta situación como una particular bonanza.

A finales de 2009 la compañía Colombian Goldfields vendió sus derechos a otra compañía canadiense, Medoro Resources Ldt ${ }^{2}$. Medoro continuó la compra de títulos a los pequeños empresarios mineros y reinició las actividades en algunas minas, planteando igualmente un proyecto de minería a gran escala cuyo inicio sería en unos cinco años ${ }^{3}$. Esta compañía también compró Mineros Nacionales, la empresa de mediana escala que opera en la parte baja del Cerro El Burro. De acuerdo con Medoro Resources,

1 Estas afirmaciones, de Ian Park, presidente de Colombian Goldfields, son tomadas del documental "Canadian mining in Colombia" realizado por la cadena de noticias CBC de Canadá, http://www. youtube.com/watch? $=\mathrm{iVWAVJL1KM8}$

2 En 2011, producto de una fusión de empresas canadienses, esta compañía pasó a denominarse Gran Colombia Gold. Sin embargo, a lo largo del texto se conservará la alusión a Medoro Resources, pues esta era su denominación cuando se realizó la investigación.

3 La exploración del potencial aurífero inició en enero de 2010. Según la legislación colombiana (el Código de Minas -Ley 685 de 2001- y la Reforma del Código de Minas - Ley 1382 de 2010), la fase exploratoria puede tardar tres años, prorrogable por dos años más; la compañía puede solicitar prórrogas adicionales de dos años hasta un total de 11 años. De acuerdo con los resultados de esta fase, la compañía determina si da inicio o no al proyecto de explotación a cielo abierto. La vigencia total del contrato de concesión que el Estado otorga a una compañía es de 30 años como máximo, pero es posible realizar una prórroga por 20 años más. 
las reservas auríferas de Marmato se calculan en 7,5 millones de onzas, los cálculos más optimistas hablan de 12 millones, que se podrían extraer en unos 20 años ${ }^{1}$.

Ante el panorama antes descrito, el apoyo institucional a la compañía (con el Ministerio de Minas y Energía a la cabeza) y la escasa capacidad de interlocución de las autoridades municipales, se ha generado un movimiento de resistencia denominado Comité Cívico Prodefensa de Marmato, que busca evitar "la destrucción del patrimonio histórico del municipio". El Consejo Regional Indígena de Caldas -CRIDEC-, también se ha vinculado a este proceso, así como organizaciones sociales y ambientales. Asimismo, se sumó la recientemente conformada Red Colombiana frente a la gran minería trasnacional, que reúne múltiples organizaciones, entre ellas, federaciones de mineros de pequeña escala de otras regiones del país.

La resistencia ante el traslado también se apoya en la inexistencia de claridad sobre las condiciones de la reubicación. La toma de decisiones sin la consulta a la población y las acciones encaminadas a diezmar la pequeña minería, han generado un sentimiento colectivo de malestar.

\section{Minería y conflictos socioambientales}

La extracción de oro puede darse desde explotaciones artesanales y de pequeña escala (tal como ocurre en poblaciones cuya historia y dinámica social y económica están ligados a esta actividad), hasta megaproyectos mineros a cielo abierto. Ambos tipos de minería tienen impactos severos sobre el medio ambiente y el territorio, pero por su magnitud, la minería de gran escala a cielo abierto genera mayores riesgos de devastación.

La megaminería representa uno de los sectores de mayor rentabilidad en la economía mundial; pero también, es el tipo de industria que despierta los más vehementes debates sobre su modo de operar y sobre las consecuencias que acarrea la práctica extractiva. Esta minería se desarrolla en superficie, mediante la remoción de la capa vegetal y la voladura de montañas, usando enormes cantidades de explosivos. Para la recuperación del oro, se utilizan inmensas cantidades de agua y cianuro, proceso que se conoce como "lixiviado con cianuro". En sus operaciones, modifica los cursos de agua y altera la composición de los suelos, causa erosión o esterilidad, haciendo difícil, si no imposible, la restauración vegetal. Los efectos sobre la salud, por los niveles de ruido, contaminación del aire y agua también están ampliamente documentados (Bebbington, Hinojosa, Humphreys, Burneo y Warnaas, 2008). La atenuación de los impactos ambientales de la minería de gran escala no ofrece perspectivas alentadoras.

1 Rueda de prensa del presidente operativo para Colombia de Medoro Resources, http://www. larepublica.com.co/archivos/EMPRESAS/2010-05-26/la-mina-de-marmato-se-explotara-encinco-anos_101079.php 
Es tal su magnitud y tales sus efectos acumulativos y de largo plazo, que las prácticas de mitigación y los esfuerzos de restauración han resultado, en muchos casos, exiguos (Bernhardt y Palmer, 2011).

A este tipo de minería se encuentran asociados complejos conflictos sociales que incluyen disputas por el territorio, pues ha sido recurrente el reasentamiento de poblaciones enteras para dar paso a la construcción de las minas, tal como se prevé en Marmato. Asimismo, a la gran minería es adjudicado el menoscabo de los modos de producción tradicionales puesto que supone, en muchos casos, el desplazamiento de la producción local, como la agricultura o la minería de pequeña escala.

La relación conflictiva entre minería y territorio está mediada no sólo por las consecuencias medioambientales que supone el trabajo minero, sino por el propio ciclo económico de la minería (generalmente inestable, por las fluctuaciones del mercado internacional), la relación empresa - Estado y los procesos de negociación con las comunidades locales (Jordan, 2008).

La desproporcionada distribución de las ganancias en los contextos en que se desarrollan los proyectos mineros es también objeto de cuestionamientos. Este último aspecto de la cuestión minera ha llevado a algunos analistas a referirse a la "paradoja de la abundancia"; es decir, el fenómeno de dependencia de la minería en el crecimiento de las regiones de bajo desarrollo económico, donde los recursos naturales no renovables son abundantes, sin que ello acarree mejoras en las condiciones de vida de las poblaciones implicadas en los proyectos mineros (Bebbington et al., 2008). Al contrario, muchos ejemplos evidencian una relación opuesta entre las espectaculares utilidades de las empresas mineras y el deterioro de las condiciones de vida de las poblaciones locales. Algunos ejemplos de esta paradójica relación se encuentran en países suramericanos con vocación minera como Chile, Bolivia y Perú ${ }^{1}$ (De Echave, 2009; Svampa, 2009; Urán, 2008).

Autores como Stiglitz (2007) defienden la idea de que es posible "escapar" de tal paradoja, sólo si en los países con abundancia de recursos naturales existen condiciones institucionales sólidas. Para este autor, un modelo extractivo exportador, sumado a formas débiles de gobierno produce efectos nefastos, especialmente en el nivel local, donde pueden confluir altos niveles de corrupción y escasa capacidad de interlocución con las corporaciones multinacionales que llevan a cabo los proyectos mineros.

1 En Colombia, algunos estudios han señalado esta relación conflictiva en las minas de ferroníquel en Córdoba y en la mina de carbón a cielo abierto más grande del mundo, El Cerrejón, en los departamentos de la Guajira y Cesar (Urán, 2008; CENSAT Agua Viva, 2010). 
La minería artesanal y de pequeña escala también es objeto de cuestionamiento. Esta es una práctica a la que a finales de la década de los años noventa se dedicaban cerca de 13 millones de personas en todo el mundo (OIT, 1999). Aunque no existe un claro consenso en la definición de este tipo de minería, suele atribuírsele un carácter informal referido a la inexistencia de títulos mineros, vínculos laborales laxos, escaso seguimiento de la normatividad relativa a la seguridad minera y a las disposiciones ambientales, poca tecnificación y reducida productividad, en contraste con los emprendimientos mineros de mayor tamaño y niveles superiores de tecnificación. Esta clasificación cobija tanto a la minería de subsistencia, que generalmente es ocasional, individual y sin mayor elaboración técnica, como a las pequeñas empresas que pueden generar empleo a más de 50 obreros.

La siguiente cita ilustra las mayores inquietudes de distintos organismos internacionales en torno a la pequeña minería en regiones donde ésta representa la única o más promisoria fuente de ingresos:

Frecuentemente los gobiernos, las grandes empresas, los ambientalistas y otros actores sociales no aprueban las actividades de la MAPE (Minería Artesanal y de Pequeña Escala). Las preocupaciones van desde el empleo de mano de obra infantil y la posibilidad de daño ambiental (en especial, a través del uso de mercurio en la minería aurífera) hasta el uso de los ingresos de la MAPE para financiar conflictos, la inquietud social y conflictos provocados por las operaciones de los 'buscadores de oro', la alta incidencia de la prostitución y la propagación del VIH/SIDA, debido a la migración de trabajadores (IIED y WBCSD 2002, p. 442).

La pequeña minería es una actividad que se contrapone en muchos aspectos a los modernos marcos normativos en materias tan diversas como las relaciones laborales, las directrices medioambientales y los volúmenes de producción. En la minería artesanal y de pequeña escala, la contaminación es asociada no sólo con el medio ambiente, sino también con el deterioro moral: prostitución, trabajo infantil y despilfarro son algunas de las imágenes asociadas al mundo de la minería artesanal. Así, la gran minería es proclamada como una oportunidad social, económica y ambientalmente "aséptica" de superar los inconvenientes de la pequeña minería.

En Colombia, uno de los puntos de debate radica en que la regulación minera, regida por la Ley 685 de 2001 o Código de Minas, privilegia y promociona la minería de gran escala, desconociendo el papel de la minería tradicional en el desarrollo de distintas poblaciones, más allá de consideraciones de eficiencia económica. La política minera reconoce que la pequeña minería corresponde a unidades mineras locales "cuyas labores están entroncadas con la cultura regional y (...) no consideran a la minería como un negocio sino como una actividad de sustento. En general, los niveles de productividad en este segmento son bajos y el impacto de su labor es más social que económico" (UPME, 2007, p. 16). Sin embargo, no existen políticas específicas para este 
tipo de minería, más allá de exhortar a los pequeños mineros a "salir de la ilegalidad"1, entrar en el juego de la competitividad y ajustarse al marco legal para la gran minería (Del Valle, 2008; Vergara, 2007).

\section{"No al oro sucio"}

Las consecuencias adversas de la megaminería metalífera a cielo abierto alrededor del mundo han generado movimientos de reprobación colectiva. Las objeciones a la minería de gran escala van desde campañas puntuales de protesta alrededor del deterioro de las condiciones de vida de las poblaciones concernidas por los proyectos mineros, hasta el cuestionamiento del consumo final de los metales preciosos. En esta última tendencia se ubica el comercio justo en la industria joyera global y el consumo ético, como la campaña internacional del No al oro sucio ${ }^{2}$. Pero más allá de las acciones de movimientos sociales sumamente heterogéneos, en algunos países y regiones, los gobiernos han adoptado medidas en contra de la megaminería metalífera, tras largos procesos de protesta social.

Una manifestación reciente del reconocimiento de los efectos devastadores de la minería de oro de gran escala, se encuentra en una resolución en la que el Parlamento Europeo exhorta a la completa prohibición en Europa del uso de las tecnologías mineras con base en cianuro, antes de culminar el año 2011, dada la alta toxicidad de esta sustancia química. En América Latina, Costa Rica es el primer país en declararse "libre de minería metálica a cielo abierto”, suspendiendo indefinidamente el otorgamiento de nuevas concesiones para este tipo de explotación minera. Algunas provincias argentinas también han dicho no a la minería metalífera a cielo abierto, mediante procesos plebiscitarios.

Ante la intensa y creciente reprobación, el sector minero internacional ha puesto en marcha distintos mecanismos para contener su negativa reputación. La creación de la Iniciativa Global para la Minería, del Consejo Mundial Empresarial para el Desarrollo Sustentable y la publicación en 2002 del proyecto Minería, Minerales y Desarrollo Sustentable, hacen parte de este esfuerzo. Dicho proyecto convoca a un "cambio cultural" frente a la minería transnacional, que es presentada como aspecto legítimo para un "desarrollo sustentable":

Minería Sustentable... obliga a reflexionar en el desarrollo tanto en el ámbito regional como local, en el bienestar humano y sus saludables efectos, en las personas 
y sus derechos básicos, en la democracia y sus lamentablemente muy habituales trabas -corrupción y falta de transparencia-, en el rol de la sociedad y las ventajas de su participación, en los mercados y los efectos de la globalización (...). Este proyecto no se pregunta por la sostenibilidad de la industria, sino por cómo la industria puede contribuir al desarrollo sustentable de regiones y países mineros (WBCSD, IIED y IDRC ${ }^{1}$, p. 11 y 12).

En este marco, la responsabilidad social empresarial se erige como estrategia para garantizar una mayor aceptación de los proyectos mineros (a través de donaciones, apertura de cooperativas de crédito, promesas de generación de empleo, y en último término, oportunidades de desarrollo local y regional basado en la minería). Ante estas acciones de "filantropía corporativa", algunos autores rebaten el papel de las grandes empresas mineras como agentes socializadores, cuyas acciones pueden coartar soterradamente las voluntades y limitar la autonomía en las comunidades (Svampa, Bottaro y Álvarez, 2009).

La minería transnacional reproduce posiciones antagónicas entre empresas y poblaciones implicadas en los proyectos extractivos. A continuación se analiza el caso de Marmato, donde actualmente coincide el proyecto de minería metalífera a cielo abierto de una compañía canadiense, con el proyecto de reasentamiento de la población. En las páginas siguientes se exploran los procesos y conflictos que subyacen a la coincidencia de ambos proyectos. Se examinan, a partir de un caso concreto, las disputas que surgen en el marco de los emprendimientos de megaminería, en un momento en que Colombia es pregonada por el gobierno y los empresarios como "país minero", y su efecto en la generación de posturas irreconciliables entre los proyectos mineros y sus detractores.

\section{Características de la minería local}

Marmato es una población minera ubicada en la región Alto Occidente del departamento de Caldas, que surgió durante la primera mitad del siglo XVI, época de expansión del dominio español en territorio americano. La extracción de oro en el territorio del actual municipio ya se practicaba en épocas prehispánicas, como parte de un importante corredor comercial fuertemente asociado a la producción orfebre en la región del Cauca Medio (Duque, 1955). Con la conquista hispánica, la economía minera conoció una marcada expansión, incentivada por la demanda de oro y el aumento de las transacciones económicas en Europa. El ordenamiento territorial en las regiones mineras se estructuró a partir del establecimiento de poblaciones cercanas a las minas (reales de minas), generando enclaves que posteriormente se transformarían en asentamientos permanentes, tal como ocurrió en Marmato.

1 Consejo Empresarial Mundial para el Desarrollo Sustentable, Instituto Internacional para el Medio

Ambiente y el Desarrollo, y Centro Internacional de Investigaciones para el Desarrollo. 
La actual cabecera de Marmato surgió como campamento minero y se transformó paulatinamente en asentamiento de los obreros de las minas y sus familias'. Éstos, en su mayor parte esclavos de procedencia africana, se constituyeron en la fuente primordial de mano de obra, luego del declive de la población indígena ${ }^{2}$. La cabecera -en la que habitan cerca de mil quinientas personas-, se fundó en la base de un cerro, denominado El Burro, y continuó su expansión siguiendo la lógica de los socavones que fueron surcándolo. Como resultado de este particular proceso urbanístico, la diseminación de las viviendas sobre el cerro y su contigüidad con las bocaminas ${ }^{3}$, y los caminos empedrados que comunican minas y viviendas, conforman un paisaje urbano apartado del tradicional damero español que predomina en muchas ciudades del país.

Además de la minería de socavón, en el municipio también tiene lugar el barequeo, mazamorreo, o minería de subsistencia ${ }^{4}$, que consiste en la extracción de oro en aluviones sin ayuda de maquinaria, pues es fundamentalmente un trabajo manual que sólo requiere de algunos elementos básicos: un cajón de madera, un saco o talego, una malla metálica, una pica y una batea para separar el oro. Esta práctica se lleva a cabo en los cañones por donde descienden los residuos del proceso de beneficio del oro de veta ${ }^{5}$ y también aquellos resultantes de la erosión en las tierras con contenido de metales preciosos.

Marmato es un enclave minero regional con una larga historia de conflictos alrededor del recurso minero, inicialmente está asociado a las más deplorables formas de esclavitud y al exterminio de la población indígena durante la conquista española. Desde finales del siglo XVIII, los litigios por la posesión de las minas eran más o menos corrientes. Durante el siglo XIX, las empresas extranjeras (inglesas especialmente) empezaron a tener protagonismo como fuentes de tecnificación de la minería local, y también como reguladoras de la dinámica social y política de la población. La tensión entre la explotación minera de pequeña escala realizada por mineros locales y la gran minería empezó a advertirse con fuerza a comienzos del siglo XX. Esta tensión fue resuelta parcialmente con la declaratoria por parte del gobierno nacional de la Zona Alta (cerro El Burro) como reserva para la minería de pequeña escala. La Zona Baja

1 La historia regional ubica la fundación de Marmato en 1537 por parte de uno de los soldados del conquistador Sebastián de Belalcázar, Juan de Vadillo, en el lugar que hoy ocupa el corregimiento de San Juan, a unos tres kilómetros de la actual cabecera, mientras ésta hacía las veces de campamento minero. El actual Marmato sólo se convierte en cabecera municipal en 1875.

2 De acuerdo con el último censo, la mayor parte de la población municipal (el 56,5\%) se reconoce como afrodescendiente.

3 Entrada a la mina. En muchos casos está soportada por una estructura de madera.

4 En el lenguaje local el término minería es reservado sólo para la actividad de socavón.

5 Se calcula que la "pérdida" de material aurífero en el proceso de beneficio es del $40 \%$ en la minería de pequeña escala.

Para citar este artículo:
Ramírez G., M. (julio - diciembre 2012). Territorialidad y conflicto en un contexto minero: el caso del municipio de Marmato, Caldas. Ánfora, 19 (33), 89 - 113. Universidad Autónoma de Manizales. ISSN 0121-6538. 
(ubicada en la base de la montaña), fue destinada para concesiones a la empresa privada; desde finales de la década de los años ochenta la empresa antioqueña Mineros Nacionales ha realizado mediana minería en esa zona.

\section{La minería como estrategia económica y de reproducción social}

El oficio minero se sustenta en una estructura de relaciones sociales e intercambios que suponen la incursión en la actividad desde edades muy tempranas, la prevalencia del trabajo masculino y la alta informalidad laboral. Los niños y jóvenes suelen involucrarse en actividades mineras, inducidos por un entorno general proclive a la minería, combinando trabajo y estudio. Los menores se ocupan tanto en la minería de socavón como en el barequeo - siendo ésta última modalidad de extracción la más común entre ellos, asumida socialmente como una forma útil de "uso del tiempo libre".

Alrededor de la minería se han gestado estereotipos relacionados con el modo de vida de los mineros, su tendencia hacia el consumo de alcohol y la prostitución. Según uno de los entrevistados, esta imagen del minero está bien fundada: "El marmateño es muy bebedor, el marmateño no, el minero, porque no es sólo en Marmato, es como la cultura del arriero, que también tiene un trabajo pesado, entonces por la noche son farras, son mujeres, juegos de azar" (Hombre, 33 años). Existe aquí una ambigüedad que se manifiesta en dos escenarios contrapuestos del campo minero. Por un lado, se brinda especial valor al trabajo y se estimula la incursión de los jóvenes en la minería, no sólo por ser un trabajo valorado socialmente sino porque se constituye en un medio (para muchos el único) de brindar apoyo económico a la familia. Por otro lado, se reconoce la vulnerabilidad de estos jóvenes frente al alcoholismo o la vida sexual prematura y "desordenada".

En Marmato se suele destacar la figura del minero como hombre bravío y fuerte, por su exposición al arduo trabajo en el interior de los socavones, especialmente en algunos oficios que requieren mucha destreza, como la apertura de galerías y la instalación de la dinamita, tareas en las que a diario se expone la vida. Aunque no se conocen índices de accidentalidad en la actividad minera de socavón, en algunas conversaciones informales se hace referencia a casos de muertes y accidentes producidos especialmente por el derrumbamiento de techos de las minas, así como explosiones de dinamita. Más que siguiendo normas técnicas de seguridad, las peligrosas condiciones del trabajo dentro de los socavones se conjuran con la devoción a San Antonio, patrono de los mineros, cuya imagen generalmente es dispuesta en la entrada de la mina o en su interior.

La población está simbólicamente identificada con la minería, a la que atribuyen en buena medida el hecho de no existir problemas de desempleo (excepto durante un reciente periodo de crisis), como ocurre en la mayor parte del territorio nacional. A su juicio, las condiciones de pobreza extrema tienen asiento en la parte norte del municipio y en el sector ubicado a orillas del río Cauca, donde muchas familias 
dependen para sus sustento de la agricultura y la pesca, actividades que no garantizan ingresos estables ni suficientes. Además, se trata de familias que no tienen entre sus integrantes hombres que se puedan dedicar a la minería o que gusten de esta actividad.

La producción a pequeña escala también ha permitido que la actividad minera tenga continuidad, a pesar de que el resultado sea irregular. De acuerdo con algunos habitantes del municipio, el alza de los precios del oro, antes que ir en su beneficio, los perjudica, pues la bonanza actual del oro en el ámbito internacional ha provocado que las multinacionales se interesen en el cerro El Burro: "[La bonanza] es una desgracia para los marmateños. Si los precios del oro están baratos es mejor para nosotros en el sentido de que no se van a interesar en esto, pero si están caros muy seguramente van a venir", la persistencia de la pequeña minería se sustenta justamente en que "se ha trabajado siempre independientemente de si [el oro] está caro o está barato, pero cuando ha estado barato, cuando no ha habido bonanza o cuando nadie se ha preocupado por eso, ahí han estado los mineros buscando la forma de subsistir" (Hombre, 44 años).

Pese a todos los problemas asociados a la minería de pequeña escala en el municipio, ésta se ha constituido en la posibilidad de permanencia de la población en su actividad tradicional, por mucho que el precio del oro fluctúe, puesto que, en palabras de un minero, "si el precio está bajo se trabaja más, si está alto se disminuye el ritmo". Lejos de la lógica de maximización de los ingresos o de acumulación de capital, la lógica de la minería local remite más bien a la preocupación por garantizar la subsistencia del grupo familiar o por sostener la continuación de la actividad.

En Marmato, la actividad minera ha sido central en la creación de íconos de identificación y en la reproducción de relaciones sociales. Según plantea Ribeiro (2004, p. 165), la identidad corresponde a modos de asumir la pertenencia, consistentes, "en reducciones de las características y diferenciaciones internas de un determinado grupo social complejo y, por definición, heterogéneo". Esta noción permite observar cómo, en la coyuntura actual, se enfatiza en un "recurso" -la identidad de un pueblo minero- como estrategia, en el juego de confrontaciones donde se trata de definir su futuro. Esto no significa que una tipificación de la identidad esté exenta de ambigüedades. Vale decir, no significa que haya acuerdo unívoco frente a la forma como se ha llevado a cabo la práctica minera, objeto frecuente de críticas por algunos pobladores. Ejemplo de ello es la objeción frente a la incursión de los jóvenes desde temprana edad en un estilo de vida calificado como pernicioso, o el cuestionamiento de las acciones de algunos dueños de minas, que han hecho un manejo irresponsable de los desechos de las mismas y que no respe102 tan los límites de su zona de explotación. 


\section{Minería y territorios "vaciables"}

El Estado es una especie de cirujano plástico, diseña el territorio y le cambia la faz para hacerlo más atractivo a la inversión.

Fernando Sánchez, CEPAL (en Antonelli 2009, p. 51)

En Marmato hay estigmatización porque hay intereses creados de compañías extranjeras, entonces a Marmato lo estigmatizan más para que le dejen el campo abierto a esas multinacionales y hacer un desplazamiento casi forzoso.

Hombre, 32 años

¿Cuáles son los límites de la expansión minera? Este interrogante forma parte de una extendida preocupación alrededor del ordenamiento y manejo del territorio y los recursos naturales en el país. Además de las implicaciones ecosistémicas, este modelo extractivo también supone, explícita o tácitamente, que el territorio es, en los términos de Svampa et al. (2009) social y culturalmente "sacrificable":

La eficacia política de estas visiones aparece asociada al carácter de los territorios en los cuales, por lo general, tienden a implantarse los megaproyectos mineros: zonas relativamente aisladas, empobrecidas o caracterizadas por una escasa densidad poblacional, todo lo cual construye escenarios de fuerte asimetría social entre los actores en pugna. Así, las comunidades allí asentadas son negadas o impulsadas al desplazamiento o desaparición y sus respectivas economías locales minimizadas, en nombre de la expansión de las "fronteras" (p. 44).

En el discurso institucional, las regalías que recibe el Estado de las empresas que extraen los recursos naturales del subsuelo, son el elemento redentor de estas poblaciones. Sin embargo, el panorama observado no corresponde a esta expectativa ${ }^{1}$. A pesar de que el municipio de Marmato ha recibido regalías durante décadas, es una zona que históricamente ha estado relegada de la inversión pública y sus habitantes así lo reconocen: "El pueblo más rico de Caldas es Marmato, el más rico y el más feo. ¿Y dónde están las regalías? Esto es para que fuera un paraíso” (Hombre, 28 años).

Mientras la presencia de oro alimenta el imaginario de región privilegiada, las condiciones de precariedad en infraestructura y servicios públicos, desdicen la imagen de

1 Este es un fenómeno extendido en los enclaves mineros. Siendo una promesa de desarrollo socioeconómico de esas regiones, los recursos procedentes de las regalías no han logrado revertir las condiciones de extrema pobreza existentes en muchas de ellas. Así, en La Guajira, donde se ubica la mina de carbón El Cerrejón, ello se debe en parte a que "estos sectores mineros tienen características de enclave y el tamaño del rezago era tan grande que los recursos de regalías son insuficientes para eliminarlo en unos pocos años" (Meisel 2007, p. 64). A esto se suman los problemas de corrupción e ineficiencia en el manejo de los dineros públicos. 
prosperidad con frecuencia vinculada a la riqueza minera. Algunos relatos sobre el papel de las minas de Marmato en la historia nacional, revelan la percepción local de la acumulación histórica de omisiones del Estado:

"La deuda social que tiene el Estado con Marmato es una deuda impagable. Volviendo a la historia, con Marmato pagamos la Independencia. Las minas de Marmato fueron pignoradas en 200 mil libras esterlinas, porque cuando la campaña libertadora Simón Bolívar no tenía con qué sostener las tropas... Así que Marmato pagó la primera deuda externa que tuvo Colombia, y si usted ve el abandono social que ha tenido Marmato. Marmato no ha tenido una carretera pavimentada y son 8 kilómetros que tiene, y en Caldas ya hay veredas o corregimientos que están pavimentados. Agua potable no hay" (Hombre, 65 años).

Frente al papel de la minería en el desarrollo del municipio existen dos perspectivas antagónicas. El lenguaje corporativo presenta a la minería artesanal y de pequeña escala como el origen los males para la población:

La pequeña minería no sostiene Marmato. Es un lugar que no tiene servicios, no se tiene acceso a la educación superior, o sea la gente allí sobrevive (...). Hay quienes hablan de preservar la cultura marmateña, y mantener el pueblo, pero lo único que la pequeña minería ha llevado a Marmato son cajas de cerveza y prostitución ${ }^{1}$.

En contraste, entre la población se destaca el hecho de que la minería de pequeña escala representa la posibilidad de continuidad del municipio. Vista desde la trayectoria colectiva, la continuidad de la minería artesanal y de pequeña escala durante cerca de cinco siglos, se vería agotada en menos de dos décadas. En cuanto a la trayectoria individual, una de las preocupaciones centrales de los mineros y sus familias es su continuación en la actividad minera, puesto que, tal como lo afirma uno de los entrevistados "La empresa no va a emplear a todos los mineros ni a mineros de 40 y 50 años...".

La pregunta que surge ante el complejo panorama de Marmato es cuáles "formas de lo global", retomando la expresión de Escobar (1993), son posibles sin que ellas conlleven el menoscabo de las condiciones de vida de sus habitantes, más allá de "soportar" o "habituarse" a las efectos indeseados de los megaproyectos mineros. Cómo, en último término, defender la continuidad del territorio y de la identidad colectiva arraigada en la minería, y al mismo tiempo enfrentarse a la coyuntura contemporánea.

1 Entrevista realizada por Mining Watch Canada y CENSAT Agua Viva (2009, p. 52 y 53) a uno de los consultores del área socioambiental contratados por Colombian Goldfields, 27 de octubre de 2008. 


\section{La transformación de un pueblo en mina}

Las multinacionales están encima de este cerro. Las empresas están llegando, comprando y demoliendo, entre más días Marmato más desolado.

No se sabe cuál va a ser el futuro de Marmato.

(Mujer, 38 años)

A mediados de la década de los 80 empezó a hacerse pública la propuesta de las autoridades departamentales de trasladar la cabecera municipal. Esta propuesta aduce la existencia de riesgos de deslizamiento, como consecuencia de las excavaciones subterráneas en el cerro El Burro, además de la acumulación de residuos procedentes de la explotación minera, los estériles, que son arrojados sobre las laderas y lechos de las quebradas. En dicho proyecto, se atribuye entonces a la minería la inestabilidad del cerro, situación que no ha hecho sino empeorar, pues "en los últimos años se ha incrementado de manera artesanal, antitécnica y desordenada, agravando el problema" (Gobernación de Caldas 1993, p. 1).

A partir de allí se generó un plan de reubicación de la población hacia El Llano, una vereda ubicada a tres kilómetros de la cabecera y que hoy forma parte de la zona de expansión urbana municipal. Más que un proyecto sistemático de reasentamiento poblacional, se ha llevado a cabo el traslado parcial e intermitente de algunas familias que habitaban en zonas de riesgo, procedentes tanto de la cabecera como del territorio rural, hacia un conjunto de viviendas denominado "Nuevo Marmato", ubicado en El Llano. En los últimos años ha crecido el interés institucional en adelantar el reasentamiento de la población. Sin embargo, para los pobladores, al menos desde la visión más generalmente compartida, y para actores de diversa índole (ambientalistas, representantes políticos, movimientos indígenas y ONG), el actual proyecto de reubicación del casco urbano tradicional obedece a la intención de facilitar a las multinacionales la explotación a cielo abierto.

Las variantes que toma la causa de la reubicación del casco urbano dan cuenta de la poca claridad del proceso. Un funcionario de la Alcaldía municipal afirma:

El traslado no se está dando por alto riesgo; el traslado se está dando por necesidad de expansión y desarrollo. No nos estamos yendo porque esto esté en riesgo. Desafortunadamente la empresa privada ha tenido un interés muy grande en Marmato y nos metió un terrorismo grande de que esto estaba en riesgo. Justamente a raíz de los estudios que están haciendo para el ajuste del Esquema [EOT], Corpocaldas [Corporación Autónoma Regional de Caldas] nos ayudó con la construcción del mapa de riesgo y determinó que sí hay una zona de riesgo, pero no es todo como decía la empresa.

El código de minas vigente (Ley 685, Artículo 35), admite las actividades mineras dentro del perímetro urbano de ciudades y poblados, salvo cuando esté expresamen- 
te prohibido el desarrollo de la minería en los Planes de Ordenamiento Territorial' ${ }^{1}$. El Esquema de Ordenamiento Territorial de Marmato, en su artículo 177, establece: "Prohíbese la explotación minera aurífera o de otros metales preciosos con sistemas mecanizados de alto rendimiento o a destajo o a cielo abierto en todo el territorio municipal". Adicionalmente, el Artículo 178 del mismo Esquema señala que "se reconoce en la pequeña y mediana minería el futuro sustentable para el Municipio de Marmato, buscando evitar ante todo la explotación a cielo abierto, a la que la comunidad ha mostrado su abierta oposición y temor de que pueda llegar a darse con resultados negativos para ésta" (Concejo Municipal de Marmato 2003, p. 67). Esta discrepancia normativa muestra las contradicciones inherentes al hecho de que la megaminería, como proyecto hegemónico, se superpone a los intereses y dinámicas locales.

Entre la población, hay quienes reconocen las implicaciones de la reciente regulación minera y prevén que ésta no augura buenas perspectivas para su territorio:

En el Código de Minas las zonas urbanas no se pueden explotar a gran escala. Eso también han tratado de cambiarlo en el Congreso, reformar el Código de Minas para que se permita explotar en zona urbana y entonces Marmato tendría explotación a cielo abierto. Quieren trasladar a Marmato y declarar al Llano zona urbana y a Marmato, la cabecera, zona rural, y poderlo explotar" (Hombre, 45 años).

Las tensiones que subyacen a las políticas locales de ordenamiento del territorio se expresan en la propia percepción de los funcionarios de la Alcaldía: "Ellos [las multinacionales] lo que más quieren es que en el EOT le metamos una palabrita, que en Marmato se podrá explotar a cielo abierto y esa palabrita nunca irá a estar en el Esquema de Ordenamiento, la vamos a discutir de todas maneras, pero nunca se va a incorporar, sería entregar el pueblo".

Frente a la posibilidad de que se realice un proyecto de gran minería también se plantea inquietud sobre las condiciones de habitabilidad en El Llano, que se verían seriamente afectadas: "El Llano sería cementerio de estériles. Al Llano tendrían que volverlo a ubicar porque esa es la pregunta que se hace todo marmateño, bueno; ellos [la multinacional] dicen que para explotar a cielo abierto procesarían 60 mil toneladas diarias de material, uno no se alcanza a imaginar cuánto es eso ;60 mil toneladas! ¿De dónde van sacar el agua para explotarla, dónde van a hacer los montajes, pero lo más preocupante, dónde va ir el material estéril?, eso no puede ir al río" (Hombre, 44 años).

El Plan de Ordenamiento Territorial es concebido por la ley 388 de 1997, como el conjunto de acciones necesarias para la planificación físicoespacial del territorio "emprendidas por los municipios o distritos y áreas metropolitanas, en orden a disponer de instrumentos eficientes para orientar el desarrollo del territorio bajo su jurisdicción y regular la utilización, transformación y ocupación del espacio, de acuerdo con las estrategias de desarrollo socioeconómico y en armonía con el medio ambiente y las tradiciones históricas y culturales". En los municipios con una población inferior a los 30 mil habitantes, el Plan recibe la denominación de Esquema de Ordenamiento Territorial. 
Pero no sólo las características geotécnicas o los problemas medioambientales hacen pensar que El Llano no ofrece las condiciones para el reasentamiento, también lo son las escasas oportunidades de empleo: "De qué vamos a vivir en El Llano, y movernos de aquí es dejarle el espacio abierto a la multinacional para que venga y acabe con todo, no existen fuentes de trabajo, no hay qué hacer en El Llano" (Hombre, 28 años).

Otros habitantes afirman que, dada la poca claridad de las condiciones medioambientales y de empleo que habría en El Llano, se generaría una diáspora, y los habitantes tendrían que irse a las ciudades. Frente a esta perspectiva, uno de los entrevistados afirma: "Yo no me veo en una ciudad como Bogotá aguantando hambre y sin nadie que me conozca para que me preste una panela, no se qué hacer. Entonces yo no me voy desplazado de Marmato para otra ciudad" (Hombre, 45 años). Uno de los problemas centrales en el caso de Marmato es que se plantea un ordenamiento esencialmente económico del territorio, y más concretamente, en una sola vía de integración al mercado mundial de metales preciosos en la lógica del capital internacional, superponiéndose a todas las demás dimensiones de la vida local.

La defensa del territorio tradicional no impide que los propios marmateños identifiquen la existencia de riesgo en su entorno inmediato. Las laderas erosionadas, el cúmulo de material estéril arrojado por las pendientes y los vertimientos en las corrientes de agua, han propiciado que el panorama que ofrece el cerro El Burro se asocie con el despropósito social y ambiental. El paisaje de riesgo que ha ido construyendo el desarrollo de la minería en el municipio, hace parte de las preocupaciones y argumentos que justifican considerar la población como vulnerable. No obstante, entre los marmateños existe una tendencia a percibir que la situación de riesgo es magnificada. Muchos de ellos están habituados a esta estructura paisajística que se ha ido imponiendo en los últimos años.

Dicha defensa del territorio está fuertemente ligada al paisaje como propiedad colectiva. El paisaje hace parte de las elaboraciones culturales sobre el territorio y la definición de las identidades colectivas. Más allá de constituirse en entorno físico, el paisaje forma parte del material discursivo a partir del cual se define la territorialidad y se elabora otro argumento central de resistencia al reasentamiento. Es importante entonces enlazar el concepto de territorialidad y su sentido frente a un proceso de reasentamiento poblacional. El territorio, visto desde su producción cultural y reproducción social, alude a la transformación significativa del espacio. Al respecto, García señala que el territorio:

Recorre un camino que le conduce desde la objetividad casi fotográfica de un paisaje humano hasta las complicadas estructuras mentales y significativas que le sustentan y le hacen humano; pasa del mundo de las cosas al de los objetos y rebelde al objetivo de las cámaras y la cartografía, se recluye en el intrincado "mapa" del lenguaje y de los símbolos (García, 1973, p. 36). 
Por su parte, la noción de territorialidad alude al conjunto de construcciones simbólicas sobre el espacio y sobre las interacciones sociales, económicas, políticas que le sustentan. En esta perspectiva, la territorialidad también hace referencia a la identidad colectiva movilizada por el sentido de pertenencia a un territorio. No corresponde a una mera elaboración subjetiva, pues como lo señala Devillard: "La continuidad humana y la permanencia en el medio se objetivan en formas de ser, de actuar y de aprehender el mundo que enlazan la vida cotidiana con la historia grupal" (2002, p. 1).

Como parte de la movilización de la identidad y el arraigo territorial frente a la posibilidad o inminencia del reasentamiento, la población apela a la ubicación privilegiada en la que se encuentra el pueblo, al paisaje que se puede apreciar desde el cerro, a sus condiciones climáticas favorables -en contraposición a las condiciones del lugar donde se planea el reasentamiento- como es común apreciar en las alusiones a las altas temperaturas de El Llano. Las características eminentemente rurales de muchas de las viviendas de la cabecera municipal, también son puestas en la balanza de pérdidas y ganancias con el nuevo asentamiento.

Muchos lugareños atribuyen al retiro de la oficina del Estado, en cabeza del Ministerio de Minas ${ }^{1}$, la degradación del paisaje y los problemas de inestabilidad de algunos terrenos: "Antes existía una figura llamada el capitán minero que se encargaba de la supervisión de todas las minas y tenía bastante autoridad y las cosas eran distintas" (Hombre, 61 años). En la coyuntura actual, convergen entre los marmateños discursos relacionados con la defensa del territorio y de su derecho de continuidad en él, mientras otro tipo de problemas se mantienen en espera, como son las condiciones de trabajo de los mineros, las problemáticas ambientales que en efecto ha generado la pequeña minería o el hecho de depender fundamentalmente de un único renglón económico. En este contexto, los habitantes de Marmato se encuentran ante dilemas radicales y ante el riesgo de desposeimiento de territorio, paisaje, recursos naturales, autogobierno y derechos culturales.

\section{Empresa y comunidad: una relación discordante}

Mientras el Estado se retrae de sus funciones reguladoras, aumenta el del papel de las grandes empresas como dinamizadoras y reguladoras del campo económico, político y social en las comunidades donde tienen injerencia. En este sentido, el

\footnotetext{
A partir de los años cuarenta del siglo XX, el Ministerio de Minas tuvo presencia directa en Marmato. Desde comienzos de la década de los años ochenta, las minas empezaron a ser administradas por la empresa estatal Ecominas. Esta empresa, que también explotaba algunos yacimientos auríferos, tenía a cargo la regulación de la minería y la administración de los molinos para el beneficio del oro. Años después, Ecominas se transformó en Mineralco (Mineros de Colombia), con funciones similares. En 1998, fue creada la empresa Minercol Ltda. como producto de la fusión de Mineralco y de la Empresa Colombiana de Carbón. En 2004, atendiendo a la lógica de no intervención estatal como empresario minero, Minercol entró en proceso de liquidación. La regulación en materia de minería es ahora atendida por la Delegación Minera de Caldas, dependiente de la Secretaría de Gobierno del Departamento.
}

Para citar este artículo:
Ramírez G., M. (julio - diciembre 2012). Territorialidad y conflicto en un contexto minero: el caso del municipio de Marmato, Caldas. Ánfora, 19 (33), 89 - 113. Universidad Autónoma de Manizales. ISSN 0121-6538. 
despliegue de responsabilidad social de las empresas respecto al impacto social y ambiental que generan sus actividades responde al modelo económico y político predominante. De acuerdo con Svampa et al. (2009) "Este nuevo modelo de acción empresarial, que surgió del Foro Económico de Davos en 1999, ha sido propuesto por y para las grandes empresas, que operan en contextos de gran diversidad, de fuerte competencia internacional y, sobre todo, de creciente exposición ante la opinión pública" (p. 47).

Actualmente la figura de la megaminería es indisociable de la llamada minería responsable en el discurso económico global. Las grandes compañías mineras se autoproclaman salvadoras no sólo de las poblaciones pobres en las que se realiza el megaproyecto minero, sino también de los ecosistemas afectados por las actividades productivas locales. Las declaraciones del presidente de Medoro Resources forman parte de este discurso tan extendido en la minería corporativa:

La realidad de Marmato es impresionante, porque en los últimos 50 años los pequeños mineros artesanales y los ilegales han contaminado la zona, acabando con todo tipo de capa vegetal y de flora. Sólo un proyecto organizado, consciente de la realidad social y ambiental, es el que puede llegar a remediar esta situación (...) Nos ceñiremos a las reglamentaciones y en particular creemos que un proyecto de estos puede ayudar a recuperar muchos de los daños ambientales ocasionados en el pasado por la pequeña minería informal. (...) Las regalías crecerán ocho veces y para ello hay un plan social, que consiste en el reasentamiento del municipio y en la generación de fuentes alternativas de empleo para el sector agroindustrial (El Tiempo, 17 de julio de 2010).

En este marco se inscriben los planes de intervención social promovidos por la empresa, con el objetivo de trabajar en el cambio de vocación del municipio hacia la agricultura y la microempresa. Es ilustrativo que los talleres realizados con la población sean anunciados como procesos de transformación de conflictos: "Ayer un conflicto, hoy una oportunidad de cambio".

Según los entrevistados, y de acuerdo con la propia observación, el proceso de reasentamiento de la cabecera carece de legitimación. Sus causas son confusas y sus procedimientos, cuestionados por la población. En síntesis, se trata de un proceso que dista de ser legitimado. Su vínculo con un proyecto de megaminería hace que la lógica original de la reubicación esté en entredicho. Una lógica que, según Machado (2009) "axiomatiza el territorio como vector de 'competitividad', espacios globales, localmente inertes, que sólo cobran valor en la medida de su 'capacidad' para captar inversiones” (p. 222). La minería de gran escala está generando la conversión del territorio, social y culturalmente dotado de relaciones y significados, en tierra vacante, valorada desde otra racionalidad, por su potencialidad mineralógica y económica. 


\section{Conclusiones}

El actual auge de la minería en América Latina está exacerbando antagonismos, posturas irreconciliables y proyectos de sociedad opuestos. La megaminería metalífera ha generado efectos medioambientales y transformaciones socioterritoriales de gran magnitud. Pese a que la industria minera invoca el control del riesgo (social y medioambiental) y la construcción de consensos y pactos de confianza con las comunidades, persisten fuertes contradicciones entre los habitantes de zonas afectadas por la megaminería.

En Colombia, mientras la política minera promociona esta actividad como camino certero para el desarrollo económico del país, en las comunidades concernidas por los grandes proyectos extractivos, se avivan los conflictos de interés y los procesos de resistencia. La relación entre minería, territorio, empresa y Estado se hace más conflictiva si se consideran los reacomodos sociales, culturales y territoriales que generan los megaproyectos (no sólo mineros) en las comunidades locales. Dichos reacomodos, cuyos efectos concomitantes son con frecuencia negativos, se realizan en nombre del "desarrollo"; desarrollo del que, paradójicamente, suelen estar marginadas las poblaciones mineras".

Esta conflictiva relación incluye disputas por el territorio tradicional, el paisaje, la autonomía local (que una pretendida descentralización no ha permitido consolidar) y la devastación medioambiental. Adicional a lo anterior, la articulación de la explotación minera con problemas de corrupción en los niveles local, regional y nacional, dificulta la aplicación efectiva de recursos que quizá podrían paliar los efectos negativos que acompañan inevitablemente toda forma de minería. Por otra parte, el Estado no ha brindado alternativas contundentes a la minería artesanal y de pequeña escala a través de incentivos o programas para mejorar las prácticas extractivas y de beneficio del oro.

Marmato, una población cuya historia e identidad están fuertemente arraigadas en la minería de pequeña escala, es un ejemplo singular de las tensas relaciones que se tejen en torno a las implicaciones de un megaproyecto minero a cielo abierto. Éste no sólo compromete la actividad minera tradicional, sino la propia existencia de la cabecera municipal, que sería reemplazada por una mina de grandes proporciones. Además, un proyecto de esta magnitud consumiría en pocos años la principal fuente de empleo de sus habitantes, probablemente sin haber hecho aportes significativos a su bienestar, ni haber creado actividades económicas de relevo, una vez finalizada la explotación minera.

1 Este es un fenómeno extendido en los países con tradición minera. El caso de la mina Yanacocha, en el Perú, es paradigmático. Es la mina de oro más grande de Latinoamérica y la segunda más grande del mundo. Está ubicada en el departamento de Cajamarca y también ha sido objeto de cuestionamientos por su forma de operar en los territorios vecinos a la mina. Siendo una de las minas más rentables del mundo, sólo el 1\% de ganancias que genera se queda en la región. Según datos de 2009 procedente del Instituto Nacional de Estadística e Informática - INEI, Cajamarca se encuentra actualmente entre los departamentos peruanos con mayores índices de pobreza. 
Además, este proyecto conduce la población a reinterpretar el sentido del plan que ya desde hace casi tres décadas se propone reasentar la cabecera municipal por motivos de seguridad. Este plan, retomado con mayor fuerza en los últimos años, se asocia para los pobladores con el interés del Estado colombiano por favorecer la realización de un proyecto de minería metalífera a cielo abierto en la actual cabecera por parte de una compañía extranjera. Esto ha incrementado la inconformidad y resistencia de los marmateños, que juzgan el proceso como un "desplazamiento forzoso" de su territorio, en exclusivo provecho de una compañía multinacional y consideran que se ha magnificado el riesgo existente para dar paso a la gran minería. Cuestionan igualmente las condiciones de su reasentamiento y las implicaciones medioambientales de la extracción de oro a cielo abierto.

El caso de Marmato plantea preguntas sobre los límites que debería tener la expansión minera en Colombia y sobre los efectos que está generando en las poblaciones y ecosistemas afectados. En esta perspectiva, las políticas y prácticas estatales deberían contribuir a la reducción de la incertidumbre colectiva, frente a aspectos tan relevantes como el empleo, el manejo del territorio, las condiciones de habitabilidad y las perspectivas de actividades económicas de relevo ante el agotamiento del recurso minero.

\section{Referencias}

Antonelli, M. (2009). Minería transnacional y dispositivos de intervención en la cultura. En Svampa, M. y Antonelli, M. (Eds.). Minería transnacional, narrativas del desarrollo y resistencias sociales. Buenos Aires: Biblos.

Bebbington, A., Hinojosa, L., Humphreys, D., Burneo, M. L. y Warnaas, X. (2008). Contienda y ambigüedad: minería y posibilidades de desarrollo. Development and change, 39 (6). Recuperado de http://www.sed.manchester.ac.uk/research/andes/publications/papers/Bebbingtonetal_Contiendayambiguedad.pdf

Bernhardt, E. y Palmer, M. (2011). The environmental costs of mountaintop mining valley fill operations for aquatic ecosystems of the Central Appalachians. Annals of the New York Academy of Sciences 1223 (2011). 39-57. Recuperado de http://www.palmerlab.umd.edu/ Bernhard_and_Palmer_2011.pdf

CENSAT Agua Viva. (2010). Conflictos socio-ambientales por la extracción minera en Colombia. Casos de la inversión británica. Cali: Merlín S.E.

Centro de Iniciativas Mineras. (2010). Producción departamental de oro en Colombia. Recuperado de http://www.imcportal.com/contenido.php?option=showpagecat\&scat $=6$

Concejo Municipal de Marmato. (2003). Esquema de Ordenamiento Territorial del municipio de Marmato. Proyecto de Acuerdo.

De Echave, J. (2009). Minería y conflictos sociales en el Perú. En De Echave, J., Hoetmer, R. y Palacios, M. (coord.). Minería y territorio en el Perú. Conflictos, resistencias y propuestas en tiempos de globalización (pp. 105-130). Lima: UNMSM, Fondo Editorial de la Facultad de Ciencias Sociales. 
Del Valle, A. (2008). Pequeña minería del oro en Colombia. ¿Pequeña minería, minería artesanal o minería de pequeña escala? Ponencia presentada en el Taller Iberoamericano de Minería Aurífera, Julio de 2008, La Habana.

Devillard, M. J. (2002). Crisis, realidades y representaciones del espacio langreano en vísperas del siglo XXI. En Los últimos mineros. Un estudio antropológico sobre la minería en España. Madrid: Siglo XXI.

Duque, L. (1955). Colombia: Monumentos Históricos y Arqueológicos 2 (179). México: Instituto Panamericano de Geografía e Historia.

El Tiempo (17 de julio de 2010). Rapidez, la clave de Medoro. Bogotá. Recuperado de http://www. eltiempo.com/archivo/documento/MAM-4057574

Escobar, A. (1993). El lugar de la naturaleza y la naturaleza del lugar: ¿ globalización o postdesarrollo? Recuperado de http://www.scribd.com/doc/31166464/Lugar-de-Naturaleza-y-NaturalezaDel-Lugar-ARTURO-ESCOBAR

García, J. L. (1976). Antropología del territorio. Madrid: Ediciones del taller de Josefina Betancor.

Gobernación de Caldas. (1993). Traslado del casco urbano del municipio de Marmato Caldas. Comité Regional de Emergencia, Oficina Departamental para la Atención y Prevención de Desastres. Colección Documento Corpes. Biblioteca Luis Ángel Arango.

Grajales, G. y Reyes, G. (2008). Estudio de impacto socio económico en Marmato. Estudio realizado por solicitud de la Secretaría de Gobierno Departamental.

Instituto Nacional de Estadística e Informática - INEI. (2009). Nota de prensa, 063. Recuperado de http://www.inei.gob.pe/

Jordán, R. (2008). Conflicto en minería: naturaleza, alcance e impacto sobre la sociedad, la economía y la industria (1980 - 2006). Informe Temático sobre Desarrollo Humano 2008. Recuperado de http://idh.pnud.bo/webportal/Portals/2/F\%20investigacion/F3\%20IDH\%20Desarro$110 \% 20 y \% 20$ Conservacion/EstudioDeCasoMineria_RJordan.pdf

Machado, H. (2009). Minería transnacional, conflictos socioterritoriales y nuevas dinámicas expropiatorias. El caso de minera Alumbrera. En Svampa, M. y Antonelli, M. (Eds.). Minería transnacional, narrativas del desarrollo y resistencias sociales. Buenos Aires: Biblos.

Mazure, L. (2010, julio). Ruée vers l'or en Colombie. Assurer la sécurité des investisseurs. Le Monde Diplomatique, p. 14.

Meisel, A. (2007). La Guajira y el mito de las regalías redentoras. Documentos de trabajo sobre economía regional 86. CEER, Banco de la República, Cartagena. Recuperado de http://www. banrep.gov.co/documentos/publicaciones/regional/documentos/2006/DTSER-86.pdf.

Metals Economic Group. (2010). Tendencias de exploración mundial. Informe especial del Metals Economic Group (MEG) para la Convención Internacional PDAC. Recuperado de http://www. metalseconomics.com/pdf/WET\%202010\%20(Spanish).pdf

Mining Watch Canadá \& CENSAT-Agua Viva. (2009). Tierras y conflicto. Extracción de recursos, derechos humanos y la responsabilidad social empresarial: compañias canadienses en Colombia. Inter Pares.

Para citar este artículo:
Ramírez G., M. (julio - diciembre 2012). Territorialidad y conflicto en un contexto minero: el caso del municipio de Marmato, Caldas. Ánfora, 19 (33), 89 - 113. Universidad Autónoma de Manizales. ISSN 0121-6538. 
Organización Internacional del Trabajo (1999). Los problemas sociales y laborales en las explotaciones mineras pequeñas. Recuperado de http://www.ilo.org/public/spanish/dialogue/sector/techmeet/tmssm99/tmssmr.htm

Ribeiro, G. L. (2004). Tropicalismo y europeísmo. Modos de representar a Brasil y Argentina. En La Antropología Brasileña Contemporánea: contribuciones para un diálogo latinoamericano, $A B A$. Buenos Aires: Prometeo Libros. pp. 165-195.

Stiglitz, J. (2007). What is the role of the State? En Humphreys, M., Sachs, J. y Stiglitz, (Eds.) Escaping the resource curse. New York: Columbia University Press.

Svampa, M. (2009). La disputa por el desarrollo: conflictos socioambientales, territorios y lenguajes de valoración. En J. de Echave, Hoetmer, R. y Palacios, M. (coord.). Minería y territorio en el Perú. Conflictos, resistencias y propuestas en tiempos de globalización. (pp. 33 - 62). Lima: UNMSM, Fondo Editorial de la Facultad de Ciencias Sociales.

Svampa, M., Bottaro, L. y Álvarez, M. (2009). La problemática de la minería metalífera a cielo abierto: modelo de desarrollo, territorio y discursos dominantes. En Svampa, M. y Antonelli, M. (Eds.). Minería transnacional, narrativas del desarrollo y resistencias sociales. Buenos Aires: Editorial Biblos.

Unidad de Planeación Minero Energética - UPME. (2007). Plan Nacional de Desarrollo Minero 2007 - 2010. Recuperado de http://www.upme.gov.co/Docs/Plan_Nal_Des_ Minero_2007_2010.pdf

Uran, A. (2008). Colombia: un estado militarizado de competencia. Las fallas estructurales para alcanzar la explotación sustentable de los recursos naturales. Tesis de doctorado. Universität Kassel. Kassel.

Vergara, V. (2007). Organización tradicional de la minería artesanal en la comunidad de "La Unión" (Municipio de Tadó, Chocó) y su introducción en las nuevas dinámicas socioculturales y de desarrollo. Medellín: Homo Habitus.

WBCSD, IIED \& IDRC. (2002). Proyecto Minería, Minerales y Desarrollo Sustentable América del Sur (MMDS). CIPMA, Santiago, CL. http://idl-bnc.idrc.ca/dspace/handle/10625/26984

\begin{tabular}{l|l} 
Para & Ramírez G., M. (julio - diciembre 2012). Territorialidad y conflicto en un contexto minero:
\end{tabular} 